\author{
Hilkka Hiiop
}

\title{
WHAT IS UNDER THE PAINT LAYER OF THE RODE ALTARPIECES?
}

In art research today, technology-based investigation that looks under and into the visible layers of a work of art has assumed an important position alongside the pictorial idiom. With the help of these examinations, information is acquired about the means and methods used to create a work of art and about the position of the work in the general studio practice of a particular artist or period.The focus of the project called "Rode Altarpiece in Close-up"1, which was started at the Art Museum of Estonia's Niguliste Museum in 2013, is to assemble material-technical information on the retable of the St. Nicholas' Church high altar to complement the detailed information related to art history ${ }^{2}$; and based thereon, to examine this monumental work in the broader context of the artistic practices of the time. In addition to the retables in Estonia, there are also plans to conduct comparative examinations on the other works attributed to Hermen Rode's workshop. The first step was taken in 2014,

DOI: http://dx.doi.org/10.12697/BJAH.2015.9.09

Translation by Juta Ristsoo.

1 A short survey of this project also appeared in an earlier issue of this journal: Hilkka Hiiop, Anneli Randla, "Medieval Painted Saints Meeting Modern Media. Project: "Rode Altarpiece in Close-Up"”, Baltic Journal of Art History, 7 (2014), 171-180. See also: http://nigulistemuuseum.ekm.ee/en/on-view/ on-view/rode-altarpiece-in-close-up/ (retrieved on 08.06.2015).

2 For the vast historiography on the retable, see e.g. Anu Mänd, "Symbols That Bind Communities: The Tallinn altarpieces of Rode and Notke as expressions of the local saints' cult", Art, Cult and Patronage. Die visuelle Kultur im Ostseeraum zur Zeit Bernt Notkes, ed. by Anu Mänd and Uwe Albrecht (Kiel: Ludwig, 2013), 136-137; Anja Rasche, Studien zu Hermen Rode (Petersberg: Imhof, 2014), 19-27; Mirjam J. Hoffmann, Studien zur Lübecker Tafelmalerei von 1450 bis 1520. (Kiel: Ludwig, 2015), 96-104. 


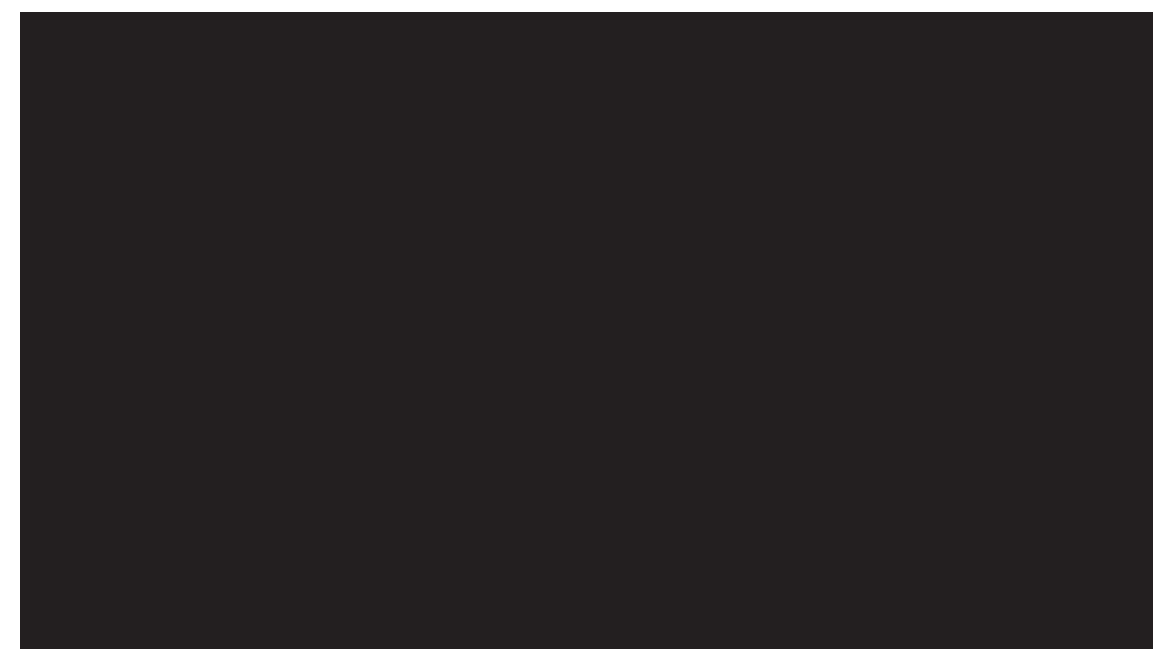

Fig. 1. Infrared analyses executed using a multispectral camera, which reveals the artist's underdrawing. Photo: Villu Plink.

when analyses were conducted of the only retable that carries Hermen Rode's signature - the so-called altarpiece of St. Luke in Lübeck. ${ }^{3}$

The following article provides an insight into the infrared analyses of two works from the Rode workshop - the Tallinn and Lübeck retables $^{4}$ - which helped to reveal the underdrawings of both art works. ${ }^{5}$ However, these are only the initial observations about the general nature of the underdrawings produced by the Rode workshop and of the particularities of each work. The infrared photos are available on the Internet ${ }^{6}$ and can be interpreted by all researchers, and therefore, this article does not claim to present any conclusive interpretations.

Relatively little is known about the work of Hermen Rode's workshop. Yet, based on the current state of the research, one can be affirm that, along with Bernt Notke's workshop, it was one of the most impor-

3 The group that conducted the examinations of the Lübeck retable: Dr. Riin Rebane (Estonian Environmental Research Centre), Andres Uueni, Hembo Pagi (Archaeovision R\&D), Dr. Signe Vahur (University of Tartu); Dr. Hilkka Hiiop, Villu Plink, Tarmo Saaret (Art Museum of Estonia).

4 The infrared analyses of both altar were executed by Andres Uueni and Hembo Pagi (Archaeovision $\mathrm{R} \& \mathrm{D})$.

5 Prior localised infrared analyses were conducted on the St. Nicholas' retable by Nikolai Bregman, a Moscow restorer and head of the conservation work on the altar from 1975 to 1991: Николай Г. Брегман,"Подслойный рисунок в алтаре Хермена Роде“, Худжественное наследие, 8/38 (1983), 87-97; no prior infrared analyses are known to have been conducted on the Lübeck retable.

6 http://iip.archaeovision.eu/rode/ (retrieved on 08.06.2015). 
tant ones in the Hanseatic centre of Lübeck in the second half of the $15^{\text {th }}$ century. ${ }^{7}$ Two masterpieces are considered to comprise the core of his surviving body of work ${ }^{8}$ : the monumental retable of the high altar in St. Nicholas' Church, which was commissioned in 1478 and arrived in 1481, and the the altarpiece of St. Luke for Lübeck's St. Catherine's Church, which is considerably more modest in size and is now located in the St. Annen Museum in Lübeck. Art historians are in disagreement regarding the completion date of the latter.

In addition to these two, a whole series of other works have been attributed to his workshop/circle, and the planned comparative technical examinations could provide significant additional information for the confirmation thereof.

One of the most effective methods for the interpretation of studio practices is infrared analysis, which enables the underdrawings under the painting layer to be revealed (if it has been executed on a light ground in a medium that is visible under infrared light, primarily one that contains charcoal ${ }^{9}$ ). The underdrawings of the Tallinn and Lübeck retables were revealed using a multi-spectral camera, which, compared to modern infrared reflectography, is an instrument with a relatively narrow range of wavelengths..$^{10}$ Therefore some of the underdrawings may remain hidden, especially under the parts of the painting executed in blue and green pigments that contain copper. ${ }^{11}$ However, the paint layers of both works were sufficiently thin that a relatively large portion of the underdrawing was revealed and therefore their nature could be assessed and compared. In addition to the drawings used to compose the visible paint layer, a whole series of charming details were exposed, which for

7 For more, see: Merike Kurisoo, "Kes oli Hermen Rode? / Who was Hermen Rode?", A Publication about the Rode-project (non-official title), ed. by Hilkka Hiiop (Tallinn: Eesti Kunstimuuseum, forthcoming).

8 One of Rode's most important works, the Grevarade diptych in Lübeck's St. Mary's Church (1494) was destroyed in 1942.

9 Jørgen Wadum, Mikkel Scharff, "Tracing the Individual "Handwriting" of Four 16th-century Artists Through Their Underdrawings", On the Trail of Bosch and Bruegel. Four Paintings United under Cross-examination, ed. by Erma Hermens (London: Archetype Publications, 2012), 60.

10 With the help of modern specially adapted mirror cameras (so-called multispectral cameras) it is possible to record wavelengths between $230-1040 \mathrm{~nm}$. The more complicated and precise solutions are based on indium-gallium-arsenides (InGaAs) infrared reflectography which are sensitive to wavelengths from 1000 to 2000nm. - Andres Uueni, Hembo Pagi, Hilkka Hiiop, "Pärandkultuuri uurimine erinevate tehniliste meetodite abil Niguliste kiriku peaaltari näitel", A Publication about the Rode-project (non-official title), ed. by Hilkka Hiiop (Tallinn: Eesti Kunstimuuseum, forthcoming). 11 David Bomford et al., Art in the Making. Underdrawings in Renaissance Paintings (London: National Gallery Company, 2002), 16. 
some unknown reason were never completed in the painting phase or were changed considerably in the course of painting (the pentimenti).

During this period, i.e. in the $15^{\text {th }}$ century, mainly two types of mediums were used to execute the underdrawing - fluid and dry. The fluid medium, some type of ink or a black pigment mixed with oil-based binding agent, was applied to the surface with a brush or pen. The underdrawings in dry mediums were executed with charcoal, black chalk or metalpoint. ${ }^{12}$ Since the artists workshops of the era were also commercial enterprises, the creation of the works of art was carefully considered, and as a rule, in addition to the master (or masters) various helpers - journeymen, apprentices, and assistants -were involved in different roles. For this, mechanisms had to be employed to optimise the work process thereby enabling a larger circle of executors to carry out the master's intent. ${ }^{13}$ For example, various methods were developed for transferring the small-scale or life-size (so-called cartoon) sketches onto the prepared surface. Templates were also used to execute repetitive elements and ornamentation. ${ }^{14}$

On the Tallinn altar produced by the Rode workshop, the existence of a very dense and detail-rich underdrawing was established, which was used to compose the entire painting in detail. The structure of the underdrawing corresponds to the traditions of the 15th century: the contours of the details and main light-dark areas are outlined along with the shaded areas that are indicated with dense hatching strokes. In places, the fabric folds are marked with characteristic hook-shaped terminations, which are, however, only visible on some of the figures (Fig. 2). The drawings seem to have been executed with a fluid medium characteristic of 15th century traditions, using either a brush or pen. ${ }^{15}$ Although the use of dry medium that allowed for greater spontaneity

12 Ibidem, 20-21; Wadum, Scharff, "Tracing the Individual "Handwriting" of Four $16^{\text {th }}$-century Artists Through Their Underdrawings", 61-63.

13 The operational mechanisms and studio practices of artists' workshops are being increasingly examined in recent years; and information based on technical analysis is what is being used for this. For example, in 2012 a conference devoted to this topic held at the National Gallery of Denmark, called "Copying, Replicating \& Emulating Paintings in the $15^{\text {th }}-18^{\text {th }}$ Century." For more, see: http://www. cats-cons.dk/conferencepast-conferences/conference_2012/; Kadi Polli, Hilkka Hiiop, "Copying, Replicating \& Emulating Paintings in the $15^{\text {th }}-18^{\text {th }}$ Century", International conference at the National Gallery of Denmark (21-22 May 2012), Technical Art History - Technics of Art History?, Proceedings of the Art Museum of Estonia, 2 (7) (2012), 229-232.

14 Bomford et al., Art in the Making. Underdrawings in Renaissance Paintings, 22-24.

15 Bomford et al., Art in the Making. Underdrawings in Renaissance Paintings, 20; 29-32. 


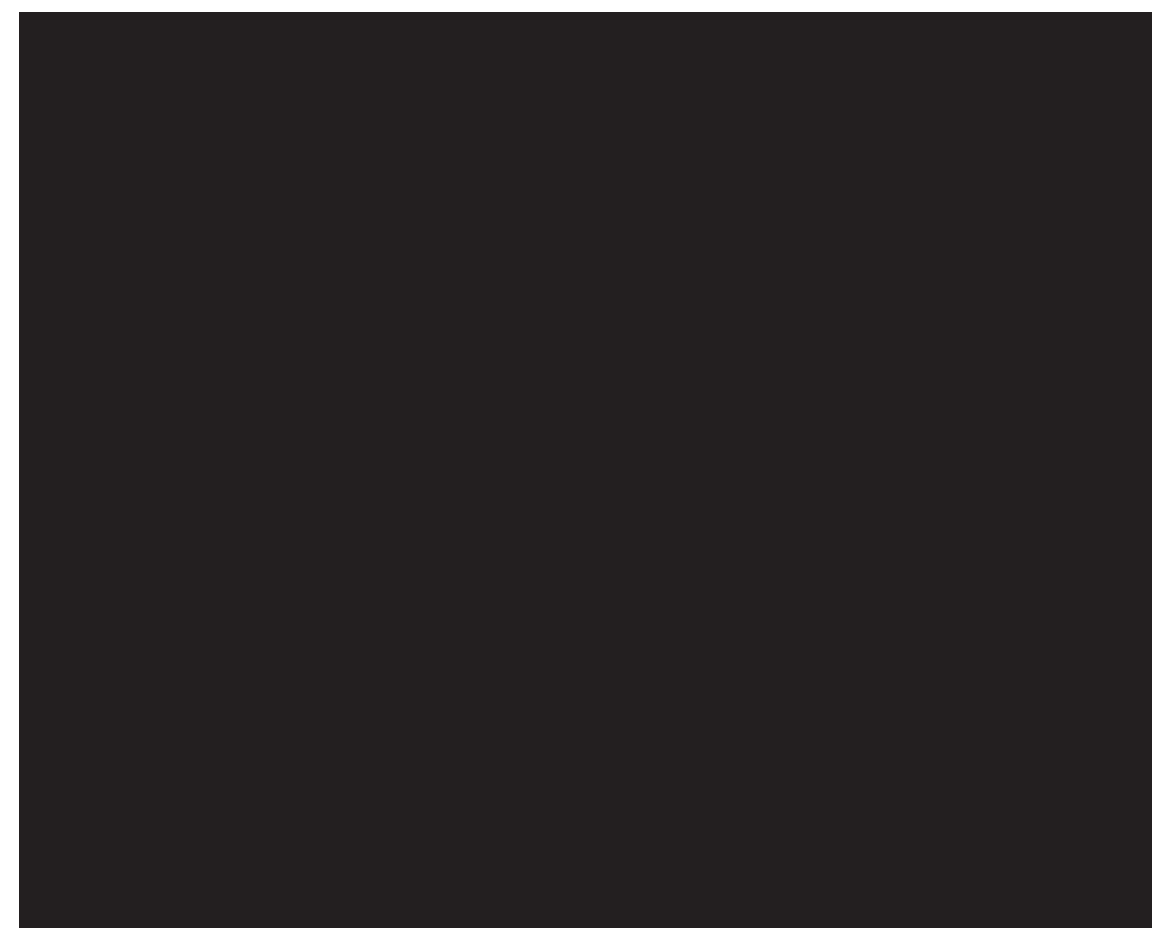

Fig. 2. The shaded areas with the dense hatching of the drapery fabric and hooked-shaped fabric folds. Photo: Hembo Pagi, Andres Uueni (Archaeovision R\&D).

gained popularity in the second half of the 15 th century ${ }^{16}$, Rode seems to have remained true to tradition.

Two stages are observable in the execution of the underdrawing. Firstly, the main elements of the composition were drawn on the ground with a relatively fine (brush) lines, and the light-dark areas marked with rapid uneven hatching. Thereafter, the main accents (although mostly for the fabric folds) were emphasised using a fluid medium of a somewhat different consistency (which appears darker under the infrared light) by using considerably more impetuous and wider lines.

In some places, the underdrawing seems to be sketchier and more spontaneous, and in others, it seems to carefully follow a given scheme. The usual practice of the artists' workshops at that time was to use sketches by the master-artist that the assistants transferred to the prepared

16 Dirk De Vos, Hans Memling. The Complete Works (London: Thames and Hudson, 1994), 379. 


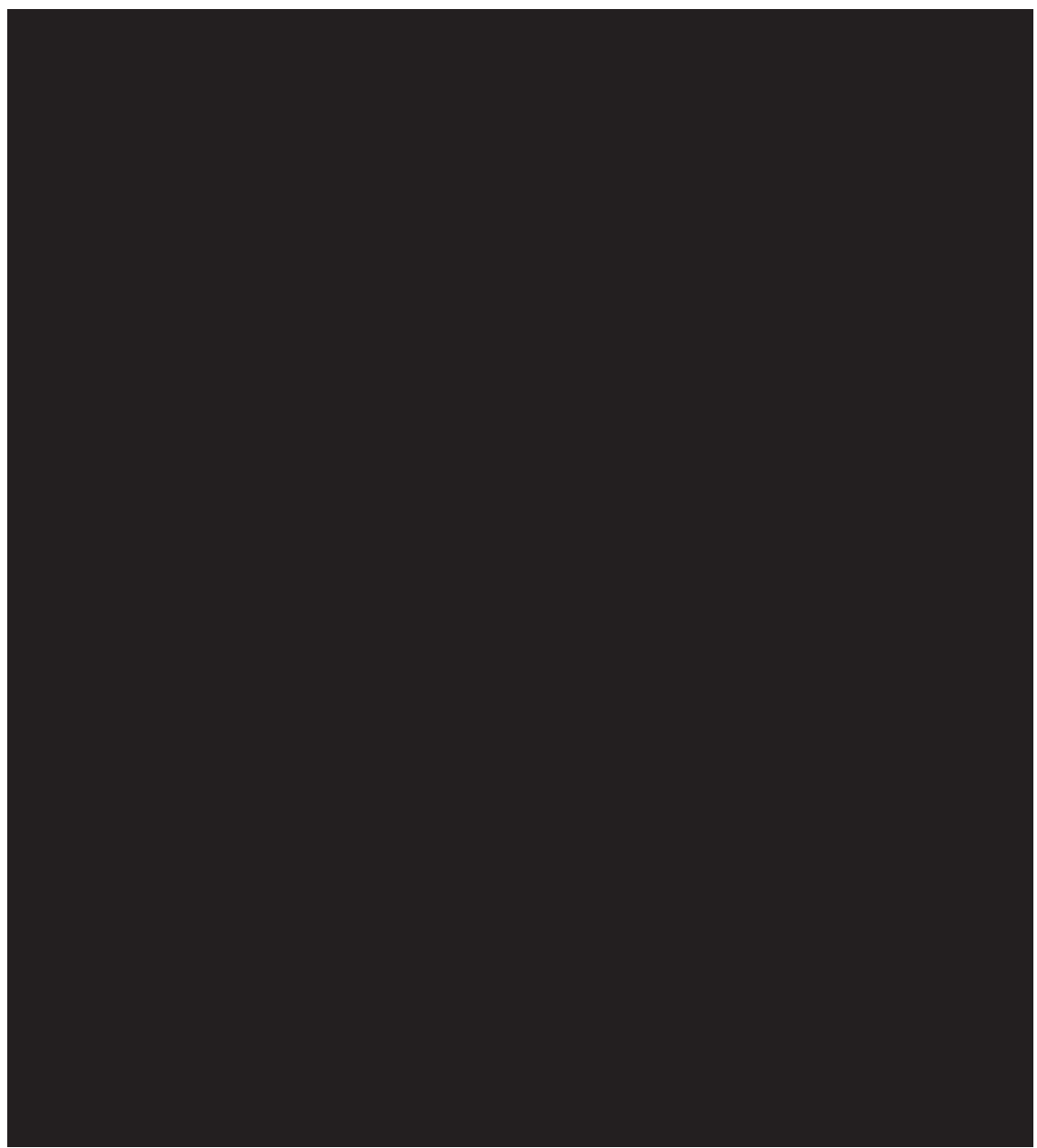

Fig. 3. The face of St. Victor in the closed position of the retable - the shift between the underdrawing and the final composition is visible on the infrared photo. Photo: Hembo Pagi, Andres Uueni (Archaeovision R\&D).

surface. ${ }^{17}$ It is quite natural to assume that in order to produce such a huge commission that needed to be completed rapidly, Rode needed a larger than usual team of assistants and well-thought solutions to realise his vision. However, no clear signs have been found that would indicate the specific method used to transfer the preparatory drawing.

17 For more, see: Bomford et al., Art in the Making. Underdrawings in Renaissance Paintings, 41-46. 
If in the case of the draperies, fabrics and various attributes/items, one could assume that a given diagram was followed, then in the case of the figures, faces, and feet, the drawing is considerably sketchier, more intermittent, searching and constructed with a network of dense and spontaneous freehand lines. Often, slight changes in the placement of the hands and faces are noticeable, as are corrections in the outlines, and a searching for the right position. Only in the case of one face is a greater compositional deviation noticeable, as if a decision had been made to change the position of the life-size cartoon (the face of St. Victor in the retable's first closed position) (Fig. 3).

Several compositional changes have also been made during the painting process and an entire series of initially planned details have been left out. As has been observed in earlier writings, ${ }^{18}$ on a picture in the bottom row of the retable in the second position, a cat can be seen scampering out from under the deathbed of Constantine, the Great apparently with a mouse or rat in his mouth through the very thin layer of paint. The emperor's chamber pot and characteristically sharp-toed slippers are also hidden under the bed (Fig. 4).

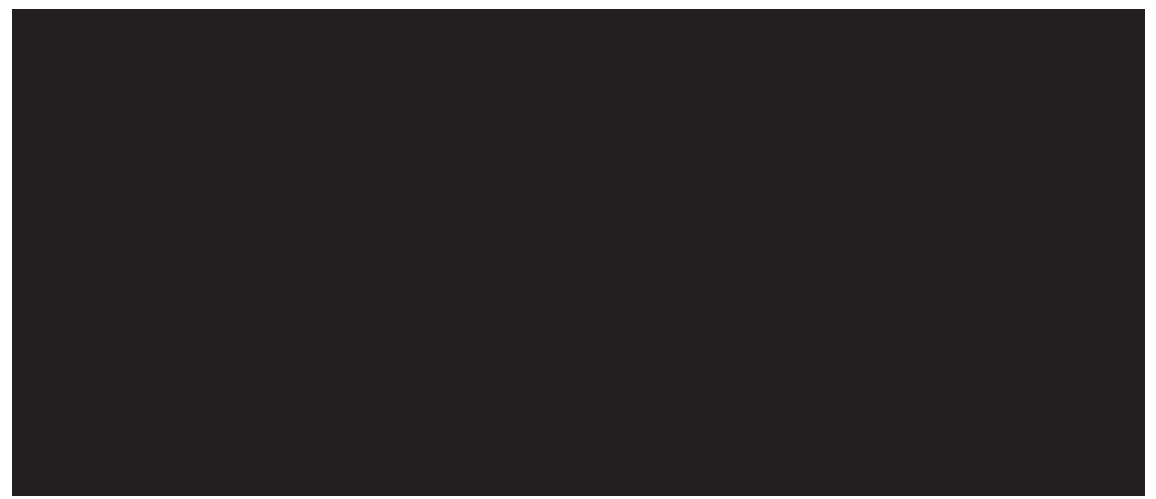

Fig. 4. Under infrared light, a cat scampering out from the deathbed of Constantine, the Great becomes visible (see left) along with the emperor's chamber pot and slippers (see right), all of which are missing from the painting layer. Photo: Hembo Pagi, Andres Uueni (Archaeovision R\&D).

18 Anu Mänd, "Kass voodi all. Ühest motiivist Hermen Rode ja Bernt Notke Tallinna retaablitel”, Kunstiteaduslikke Uurimusi 1-2 (21) (2012), 231-243. 


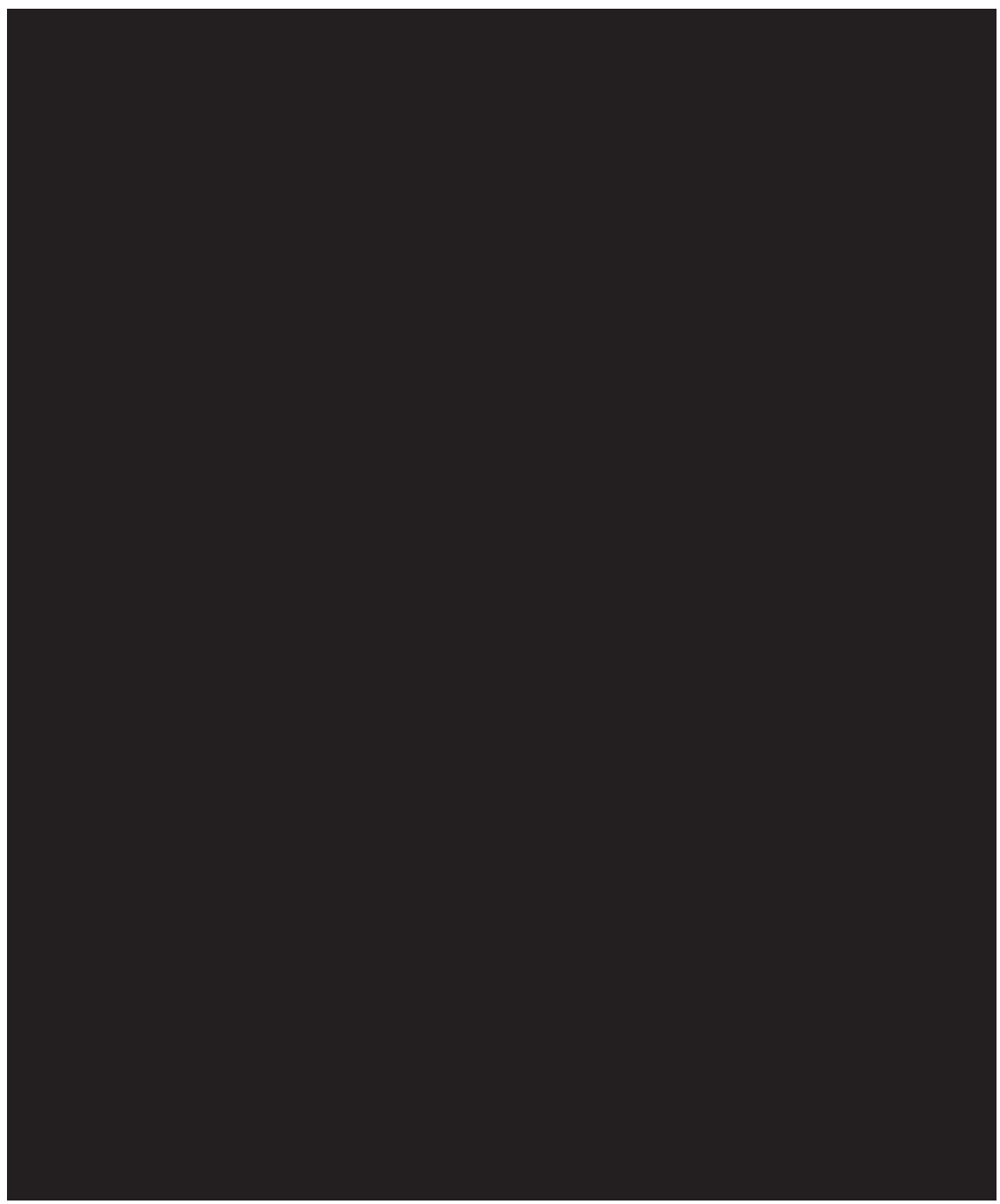

Fig. 5. A and B. The three ships that were originally planned for the river that flows out of the city (photo a) have not been painted for some reason (photo b). Photo: Hembo Pagi, Andres Uueni (Archaeovision R\&D).

On the lower right painting area of the retable in the open position, which depicts the scene of St. Victor's body being cast in the water against a panorama of Lübeck, three boats were initially depicted on the Wakenitz River that flows out of the city: a large high-masted ship moving in the direction of the viewer, a proud Hanseatic $\operatorname{cog}$ in profile and a small simple boat in front of it (Fig. $5 \mathrm{a}$ and b). 
Fig. 5. A and B. The three ships that were originally planned for the river that flows out of the city (photo a) have not been painted for some reason (photo b). Photo: Hembo Pagi, Andres Uueni (Archaeovision R\&D).

Several compositional changes can also be seen on the altarpiece in its closed position. The most amusing of these is the small wiggly "tail" that was originally drawn between the legs of the armoured figure of St. George. The coats-of-arms of the donors, which are located in the lower zone of the painting areas on the outer wings - the Great Guild's 


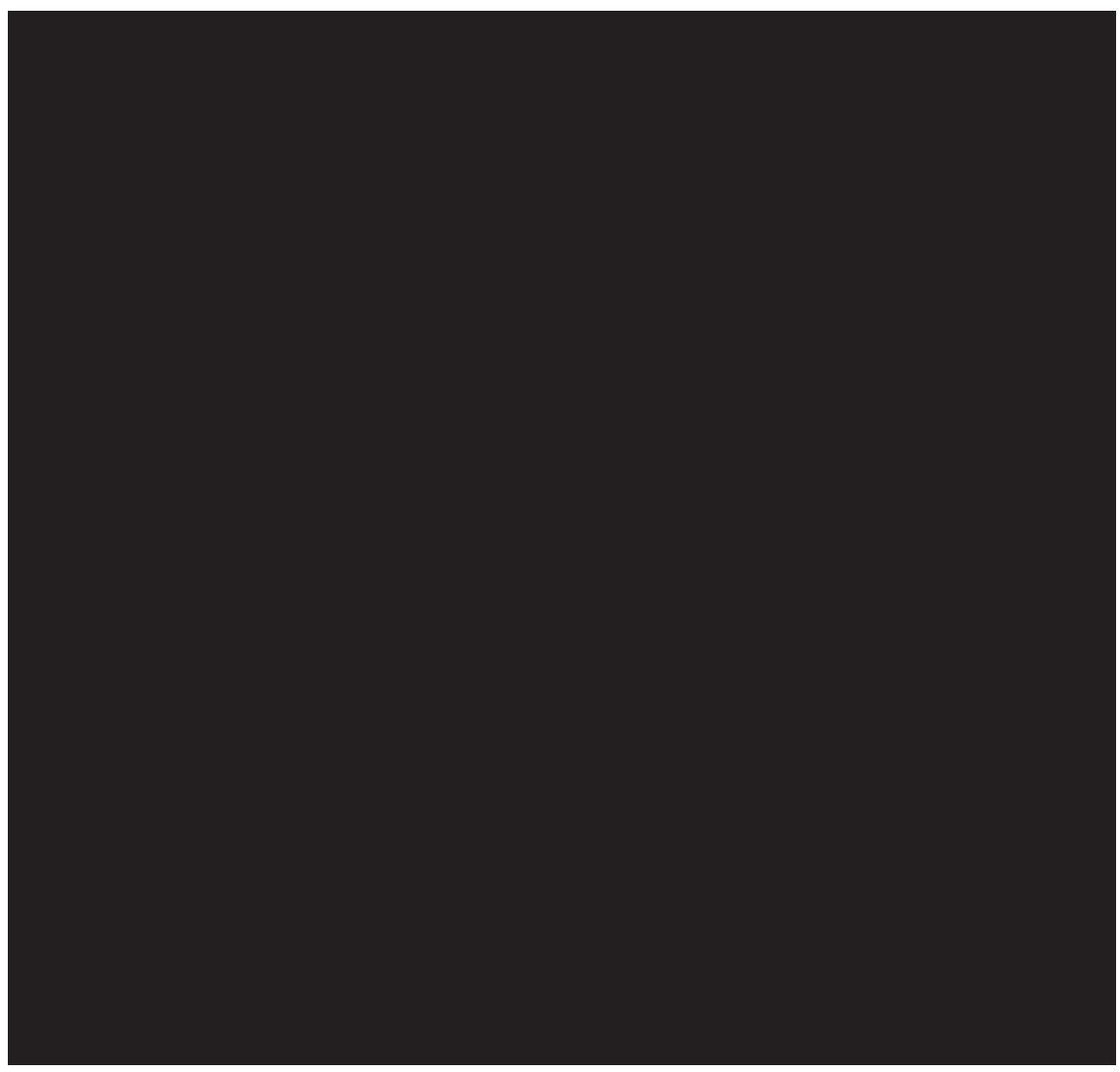

Fig. 6. The Negroid profile on the Black Heads' coat of arms was initially painted with facial features more typical of the white race. Photo: Hembo Pagi, Andres Uueni (Archaeovision R\&D).

coat of arms on one panel and the Confraternity of Black Heads' on the other - have both been adjusted a bit in the course of the painting. It is curious that the Negroid profile on the Black Heads' coat of arms was not given the features characteristic of its race until the painting stage. Initially, the profile seems to have been of a white man with a straight nose and narrow lips (Fig. 6).

If the underdrawing of the Tallinn retable is carefully composed; filled with details and many smaller and larger compositional changes, in a sense, the underdrawing of the Lübeck altar is its opposite. The figures are indicated only with a few exact lines and hatching and they correspond almost completely to what appears on the painting layer. A slightly sketchier, but again a laconically executed, freehand under- 
drawing is visible on the outer wings and predella. At the same time, the character of the drawing and the nature of lines correspond to the St. Nicholas retable and, based on the extremely similar nature of the paint layer, confirm its attribution to the same master. Only one surprising and, in the case of the St. Luke's retable, an exceptional pentimenti was identified on the second panel on the lower left of the second position (the scene of St. Luke's entombment), which might provide an additional hint regarding the issue of the retable's unclear date of completion. Namely, in the lower portion of this pictorial field, a gravestone is depicted with the date "ANNO 1484". For a long time, this was thought to be the date when the altar was completed. But subsequently researchers have dated the altar to a later period (more likely the $1490 \mathrm{~s}^{19}$ ) and the year on the gravestone has been connected to the memory of Johannes Stenrat. Stenrat was one of Lübeck's best known woodcarvers, who had actively collaborated with Hermen Rode, and is known to have died in that year. ${ }^{20}$ However, the infrared examination brought to light a relatively unusual rethinking, which is exceptional in the context of the St. Luke's altar. It seems that a gravestone was not planned at all in the initial composition, since the ropes for lifting the coffin into the grave continue under the stone. The gravestone seems to be added to the composition later and the location of the ropes was shifted (Fig. 7 $\mathrm{a}, \mathrm{b}$ and $\mathrm{c})$. Can this be considered to be simply an incidental change of plans? Or should the date on the stone be connected to Stenrat's death and the hypothesis that an important member of the Guild of St. Luke and Rode's collaborator dies while the painting is being executed and it becomes necessary to make this compositional change in his honour.

But how does one explain the great differences in the relative importance of the underdrawings of the Tallinn and Lübeck retables? One could speculate that this can be connected to the story of how the paintings were commissioned and executed. Realizing the retable for Lübeck was

19 Peter Tångeberg considers the rich polychromy (German: Fassung) of the sculptures visible in the altarpiece's third position to be untypical of Rode and suggest a date of the 1490s for the sculptures.Peter Tångeberg, Holzskulptur und Altarschrein: Studien zu Form, Material und Technik Mittelalterliche Plastik in Schweden (München: Callwey, 1989), 219. Whether the new date could be expanded to include the entire altar is unclear. Corpus der Mittelalterlichen Holzskulptur un Tafelmalerei in Schleswig-Holstein, I, ed. by Uwe Albrecht (Kiel: Ludwig, 2005), 250.

20 It has been assumed that the date on the gravestone is not the date of retable, but the date of death of a prominent member of the Confraternity of St. Luke. Since Johannes Stenrat died in that year, the year is associated with the date of his death - Corpus der Mittelalterlichen Holzskulptur un Tafelmalerei in Schleswig-Holstein, 250-257. 


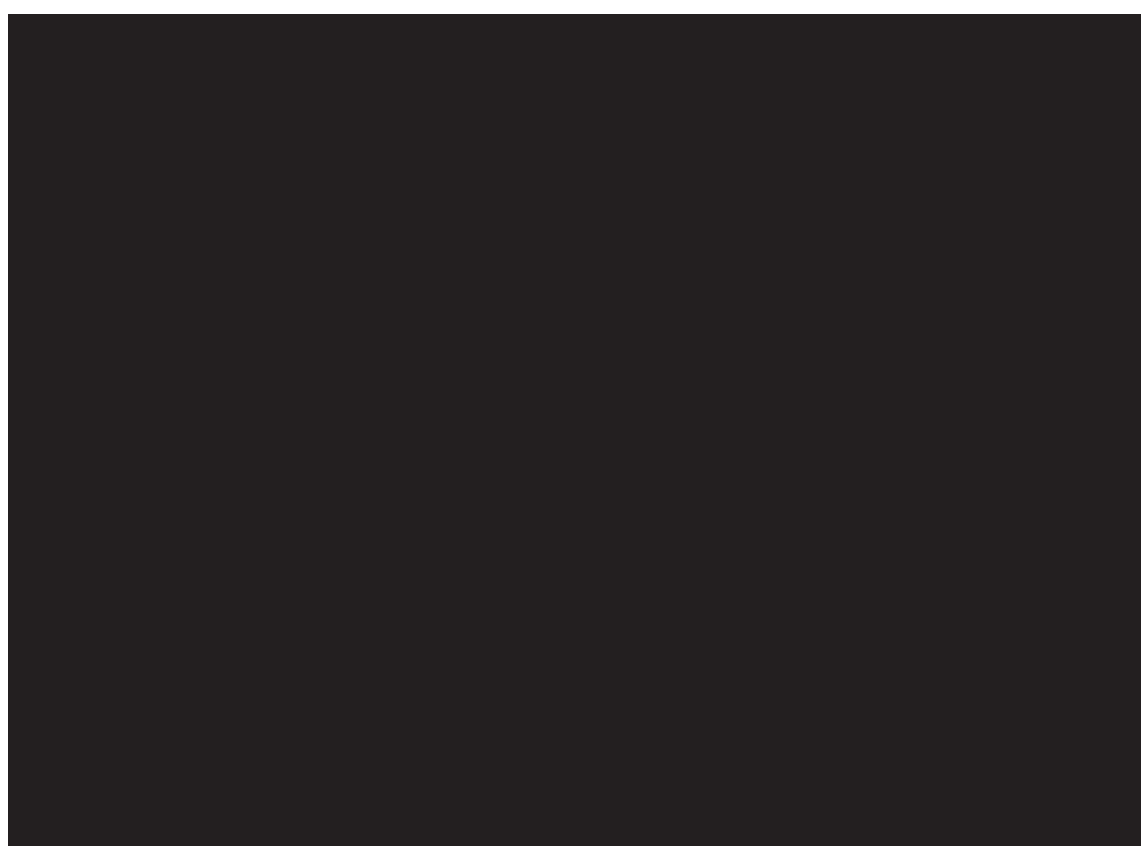

Fig. 7. A, B and C. From the scene of St. Luke's entombment on the pentimenti of the St. Luke's retable: on the underdrawing, the ropes for lowering the coffin extend under the gravestone, as if the initial composition had been altered by adding the gravestone. Photo: Hembo Pagi, Andres Uueni (Archaeovision R\&D). 


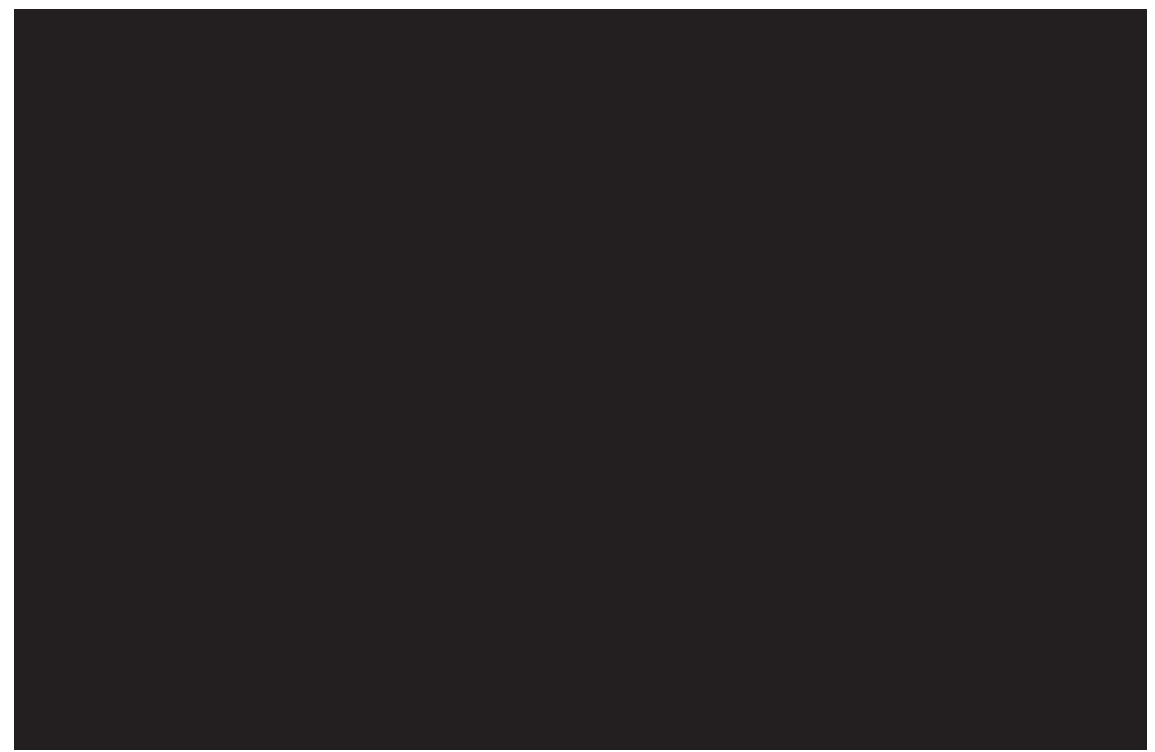

apparently one of the most significant commissions for Hermen Rode, since it was to be installed in St. Catherine's Church in his hometown, on the altar of the Guild of St. Luke, the most important organisation for artists and glaziers. ${ }^{21}$ The importance of the commission is confirmed by that fact that the master apparently painted his own portrait on the retable along with his signature - Hermen Rode - on the figure's collar. Considering the importance of the commission, one can assume that the artist made a greater than usual contribution to the execution of the retable himself and made less use of his helpers. This means that, as such an experienced and capable master, he had no need for such a thorough preliminary composition.

On the other hand, the St. Nicholas' retable was a commission from Tallinn, a faraway Hanseatic town. It was also huge in size and the completion deadline was relatively short. From the documents we know that the commission for the retable was dispatched to Lübeck in 1478 and the completed work arrived here in $1481^{22}$, i.e. a maximum of three years was spent on the execution. Considering the volume of the work - from the acquisition of the materials and construction of the frame to

21 Mirjam J. Hoffmann, Studien zur Lübecker Tafelmalerei von 1450 bis 1520 (Kiel: Ludwig, 2015), 87.

22 Mai Lumiste, Rasmus Kangropool, Niguliste kirik (Tallinn: Kunst, 1990), 38-39. 
the carving of the all the extremely fine details - the painting process had to proceed quite rapidly. The master probably involved a considerably larger team than the few assistants that could usually be found in an artist workshop at that time. ${ }^{23}$ In order to carry out the master's plan, a thoroughly prepared composition was required in the form a sketch and underdrawing. Can we assume that more hands were involved already during the transfer of the underdrawing than just the master himself (examining the nature of the fabric folds, one can assume that some mechanical transfer method was used), but when it comes to the faces, hands and other more complicated parts the master's own inquisitive freehand line is visible? Although it is almost impossible to identify different handwritings in the painting layer, it is quite likely that it was executed by a larger group of assistants. The very detailed underdrawing created the precondition for this.

This may also be the reason why many tiny details were left out in the final painted composition, for which no clear ideological reasons seems to exist. Was the delivery deadline for the altar approaching quickly, the work had to be dispatched to Tallinn and therefore some of the planned details had to be eliminated?

Thanks to today's developing and more available technology, the examination and comparison of underdrawings has become a tool that is used increasingly in interpretations related to art history. This not only provides the joy of discovering hidden secrets, but also information that expands the knowledge about the traditions of artistic practices. Future infrared analyses can provide much additional information on Hermen Rode's technically little-researched body of work, his workshop's practices and the comparison of the works attributed to him. The underdrawings of the two retables provide an idea of Rode's handwriting under the paint layer and interpretative space for all the researchers dealing with the topic. The assumptions presented here are only the initial observations and ideas of one researcher, which definitely do not claim to be the final answers, if they even exist.

23 The size of the artists' studios varied and it is difficult to determine the exact number of assistants. However, from the regulations in Cologne in the early 15th century, it is known that painters could only have one apprentice and elsewhere in Germany two. The number of trained journeymen was not limited; the workshop master could hire as many as he needed. - Bomford, Art in the Making. Underdrawings in Renaissance Paintings, 41-42. 
Hilkka Hilop: What is Under the Paint Layer of the Rode Altarpieces?

Keywords: Multispectral Investigation; Infrared Analyses; Underdrawing; Hermen Rode

CV:

Hilkka Hiiop $(\mathrm{PhD})$ is the conservation specialist in Art Museum of Estonia as well as the assistant professor and coordinator of the artefact conservation branch at the Estonian Academy of Art, Department of Conservation. She has studied and worked as a conservator in Berlin, Amsterdam and Rome, supervised a number of conservation and technical investigation projects in Estonia, curated exhibitions, and carried out scientific research on topic of conservation and technical art history. 
